\title{
Conference Paper ZnO Thin Film Deposition for TCO Application in Solar Cell
}

\author{
S. Agrawal, R. Rane, and S. Mukherjee \\ Facilitation Centre for Industrial Plasma Technologies (FCIPT), Institute for Plasma Research (IPR), Gandhinagar Plot No. A-10/B, \\ Electronic Estate, GIDC, Sector 25, Gandhinagar, Gujarat 382044, India
}

Correspondence should be addressed to S. Agrawal; sag.agr@gmail.com

Received 5 January 2013; Accepted 3 April 2013

Academic Editors: P. Agarwal, B. Bhattacharya, U. P. Singh, and B. Sopori

This Conference Paper is based on a presentation given by S. Agrawal at "International Conference on Solar Energy Photovoltaics" held from 19 December 2012 to 21 December 2012 in Bhubaneswar, India.

Copyright (C) 2013 S. Agrawal et al. This is an open access article distributed under the Creative Commons Attribution License, which permits unrestricted use, distribution, and reproduction in any medium, provided the original work is properly cited.

$\mathrm{ZnO}$ is a well-known suitable candidate for the Transparent Conducting Oxide (TCO) layer of thin film compound solar cells. In this paper we have discussed the deposition of $\mathrm{ZnO}$ thin film on glass substrate by reactive DC magnetron sputtering using oxygen as a reactive gas. Samples are prepared by varying oxygen flow rates during the deposition process. After deposition, samples are annealed at $300^{\circ} \mathrm{C}$ for 2 hours in vacuum environment. All the properties of the film are measured before and after annealing. All the samples are tested for the optical transparency, band gap, and electrical resistivity before and after annealing. Band gap of film is observed to be $3.2 \mathrm{eV}$. XRD and SEM measurements of the samples show the variation in the crystal structure and surface morphology of the film with varying oxygen flow rate and annealing also. Around $600 \mathrm{~nm}$ thick $\mathrm{ZnO}$ film with $1.5 \times 10^{-3} \Omega \cdot \mathrm{cm}$ resistivity and $80 \%$ transparency without any doping is achieved.

\section{Introduction}

$\mathrm{ZnO}$ has attracted attention as Transparent Conducting Oxide (TCO) because of its large band gap $(3.3 \mathrm{eV})$, low resistivity $\left(5 \times 10^{-4} \Omega \cdot \mathrm{cm}\right)$, abundance, and nontoxicity. Optoelectric properties of $\mathrm{ZnO}$ depend on deposition and postdeposition treatment conditions as these properties change significantly with the conditions like nature of chosen doping element, the adsorption of oxygen during the deposition process, film deposition temperature, and postdeposition annealing atmosphere [1].

Singh et al. [1] has shown that the lowest resistivity was found at $300^{\circ} \mathrm{C}$ deposition in oxygen environment. Our aim is to show that if the film is annealed at $300^{\circ} \mathrm{C}$ after deposition in reducing environment, it would show much lower resistivity $\left(\sim 10^{-3} \Omega \cdot \mathrm{cm}\right)$.

Magnetron sputtering is a well-known technique of depositing $\mathrm{ZnO}$ thin film [2]. In the present study, we have investigated the effect of oxygen partial pressure during film deposition by DC magnetron sputtering technique and annealing in reducing environment after deposition. The purpose of this work is to determine the deposition and treatment conditions that can produce highly conducting and transparent $\mathrm{ZnO}$ film for thin film solar cell application.

\section{Experimental}

Figure 1 shows the schematic of the experimental setup for magnetron sputtering deposition. Distance between the target and substrate was $\sim 15 \mathrm{~cm}$. Base pressure of the system was $2 \times 10^{-5} \mathrm{mBar}$. Total operating pressure during deposition was $5 \times 10^{-3} \mathrm{mBar}$. Deposition is done in a mixture of argon and oxygen gases. $\mathrm{Zn}$ target of $3^{\prime \prime}$ diameter, $5 \mathrm{~mm}$ thick, and $99.999 \%$ purity is used for sputtering. Deposition power was around $\sim 275 \mathrm{~W}$. Deposition process is performed for 1 hour. Total five samples are deposited by varying the oxygen percentage in argon. Deposition parameters (oxygen percentage with sample ID no.) are shown in Table 1.

After deposition, all the samples are annealed in reduced environment $\left(\sim 2 \times 10^{-5} \mathrm{mBar}\right)$ for two hours at $300^{\circ} \mathrm{C}$. Annealing treatment profile is shown in Figure 2. 


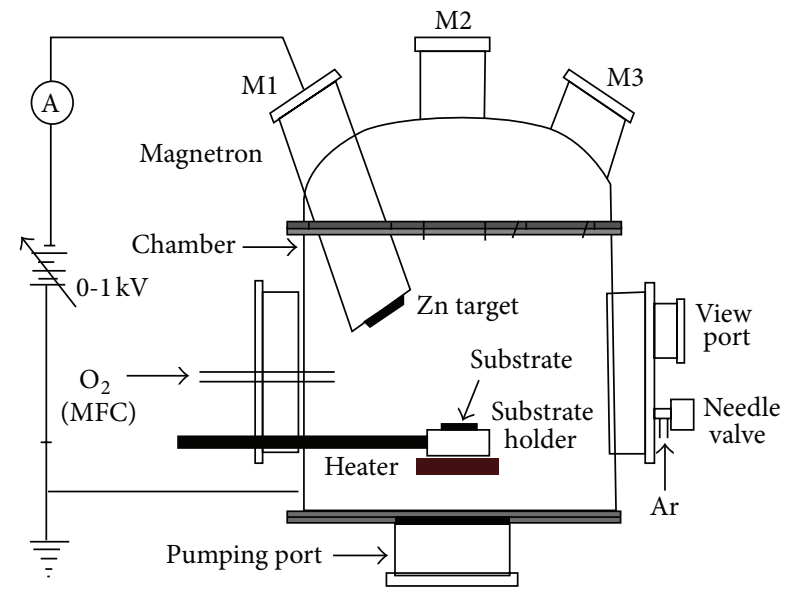

FIGURE 1: Experimental setup.

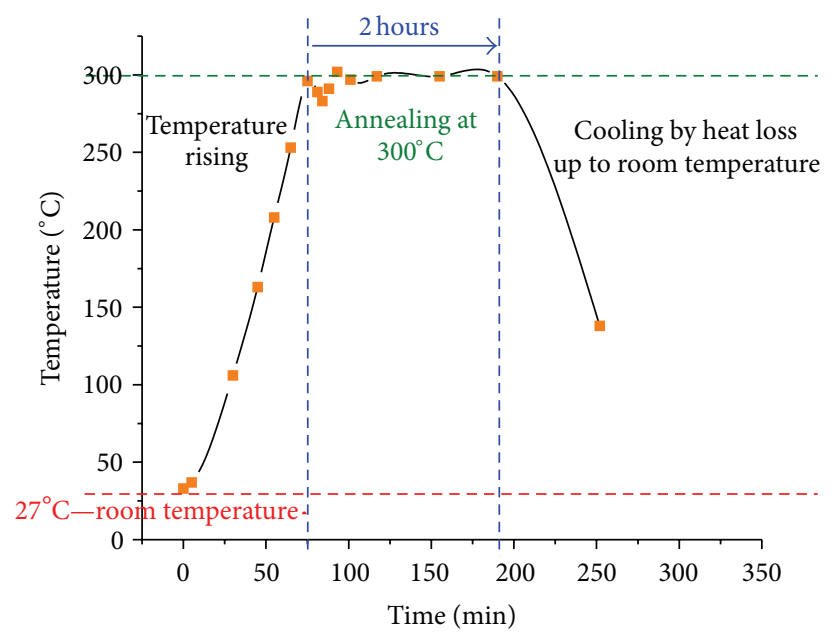

Figure 2: Postdeposition annealing treatment profile.

TABLE 1: Deposition parameters.

\begin{tabular}{lccc}
\hline \multirow{2}{*}{ Sample ID } & Total operating pressure & \multicolumn{2}{c}{ Oxygen variation } \\
Unit & mBar & SCCM & $\%$ \\
\hline A & $4 \times 10^{-3}$ & 13.5 & $25 \%$ \\
B & $4.5 \times 10^{-3}$ & 12.5 & $21 \%$ \\
C & $4.5 \times 10^{-3}$ & 11.5 & $19 \%$ \\
D & $5 \times 10^{-3}$ & 10.0 & $17 \%$ \\
E & $5 \times 10^{-3}$ & 09.0 & $14 \%$ \\
\hline
\end{tabular}

\section{Results and Discussion}

Around $600 \mathrm{~nm}( \pm 10 \%)$ thick films are deposited in argon and oxygen environments. Resistivity of all samples is measured using four-probe method. Transparency and band gap (band gap is being measured using Tauc method and while measuring bad gap reflection of the film is being assumed zero) are measured using UV-Vis (190-1100 nm) spectrophotometer. Results are shown in Tables 2 and 3.

3.1. Transparency and Band Gap. Figures 3, 4, and 5 show the transparency measurements of the films. Figure 5 clearly shows that annealing process does not affect the transparency in considerable amount, but as the oxygen percentage increases in deposition process, transparency increases.

Band gap of the films is found $\sim 3.2 \mathrm{eV}$.

3.2. Resistivity. Figure 6 clearly shows that resistivity of the film varies with oxygen percentage and high for higher oxygen percentage for as deposited samples But after annealing in reduced environment, resistivity of the all samples go down up to $\sim 10^{-3} \Omega \cdot \mathrm{cm}$ due to desorption of extra oxygen in vacuum environment at $300^{\circ} \mathrm{C}$.

3.3. XRD. Figure 7 shows the XRD results of the samples before annealing. It is clear that the film is made of mixed 
TABLE 2: Results of deposited film before annealing.

\begin{tabular}{lccccc}
\hline Sample ID & Sheet resistance of the film & Thickness of film & Refistivity of the film & Transparency of the film & Band gap of the film \\
Unit & $\Omega$ & $\mathrm{nm}$ & $\Omega \cdot \mathrm{cm}$ & $\%$ & $\mathrm{eV}$ \\
\hline A & High $^{* *}$ & 550 & High $^{* *}$ & 81.6 & 3.14 \\
B & 2.27 & 650 & $6.69 \times 10^{-2}$ & 87.3 & 3.12 \\
C & 7.116 & 710 & $2.29 \times 10^{-1}$ & 87.3 & 3.14 \\
D & 0.304 & 530 & $7.30 \times 10^{-3}$ & 60.2 & 3.0 \\
E & 0.216 & 530 & $5.19 \times 10^{-3}$ & 60.3 & 3.12 \\
\hline
\end{tabular}

**High Resistivity means it is such high that is not in the measurement range of the available four-probe instrument at our lab.

TABLE 3: Results of films after annealing treatment.

\begin{tabular}{|c|c|c|c|c|c|}
\hline \multirow{3}{*}{$\begin{array}{l}\text { Sample ID } \\
\text { Unit }\end{array}$} & \multicolumn{5}{|c|}{ After annealing at $300^{\circ} \mathrm{C}$ for $2 \mathrm{Hrs}$ in vacuum $\left(2 \times 10^{-5} \mathrm{mBar}\right)$} \\
\hline & Sheet resistance of the film & Thickness of film & Resistivity of the film & Transparency of the film & Band gap of the film \\
\hline & $\Omega$ & $\mathrm{nm}$ & $\Omega \cdot \mathrm{cm}$ & $\%$ & $\mathrm{eV}$ \\
\hline A & 0.0616 & 650 & $1.81 \times 10^{-3}$ & 84.2 & 3.19 \\
\hline B & 0.041 & 830 & $1.54 \times 10^{-3}$ & 80.8 & 3.2 \\
\hline $\mathrm{C}$ & 0.457 & 580 & $1.20 \times 10^{-2}$ & 85.9 & 3.2 \\
\hline $\mathrm{D}$ & 0.0903 & 640 & $2.62 \times 10^{-3}$ & 74.2 & 3.1 \\
\hline E & 0.0445 & 645 & $1.30 \times 10^{-3}$ & 61 & 3.18 \\
\hline
\end{tabular}

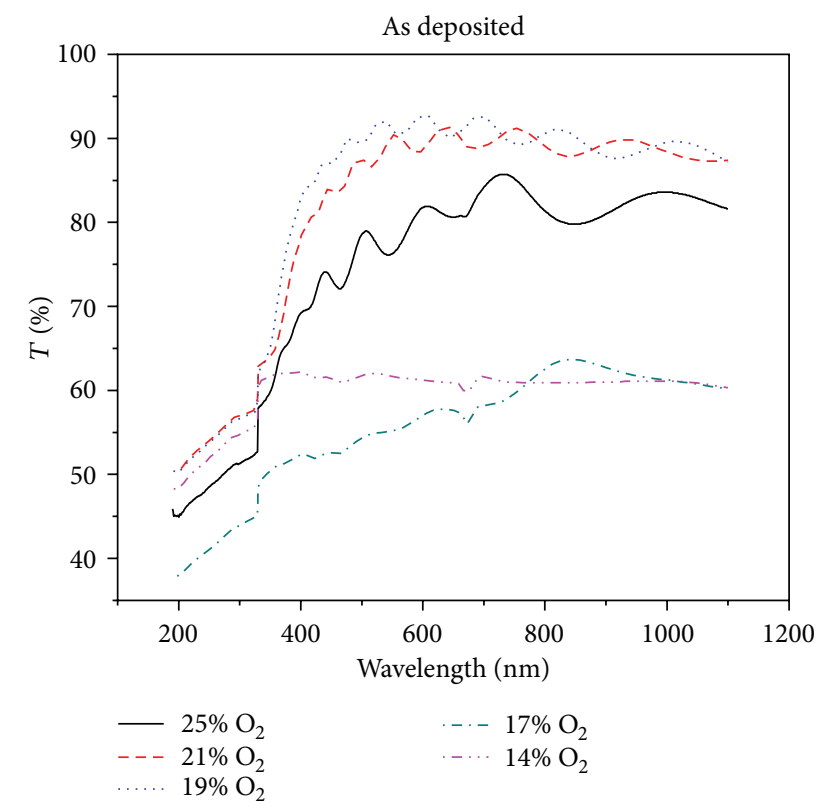

FIGURE 3: Transparency with oxygen percentage before annealing (as deposited).

phase of hexagonal phase and Face Centered Cubic (FCC) phase of $\mathrm{ZnO}$ and hexagonal phase of $\mathrm{Zn}$. It is clear that films deposited in high oxygen percentage environment are crystalline compared to the films deposited in $14 \%$ and $17 \%$ oxygen environment. It is clear that film formation in hexagonal face is more preferred than FCC phase for

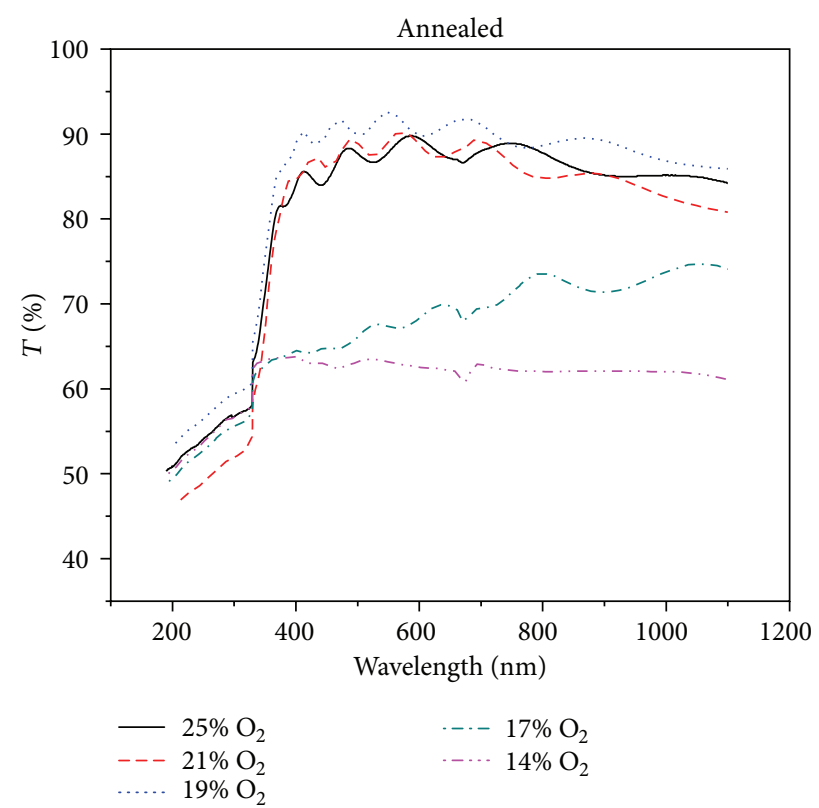

FIGURE 4: Transparency with oxygen percentage after annealing.

deposition in higher oxygen percentage environment. Film deposited in 19\% oxygen environment is more crystalline as it shows the most intense (002) peak of hexagonal phase. But $\mathrm{Zn}$ phase peak (101) is clearly shown in the film deposited in $14 \%$ oxygen environment. It is a clear indication of less $\mathrm{ZnO}$ formation in less oxygen presence. 


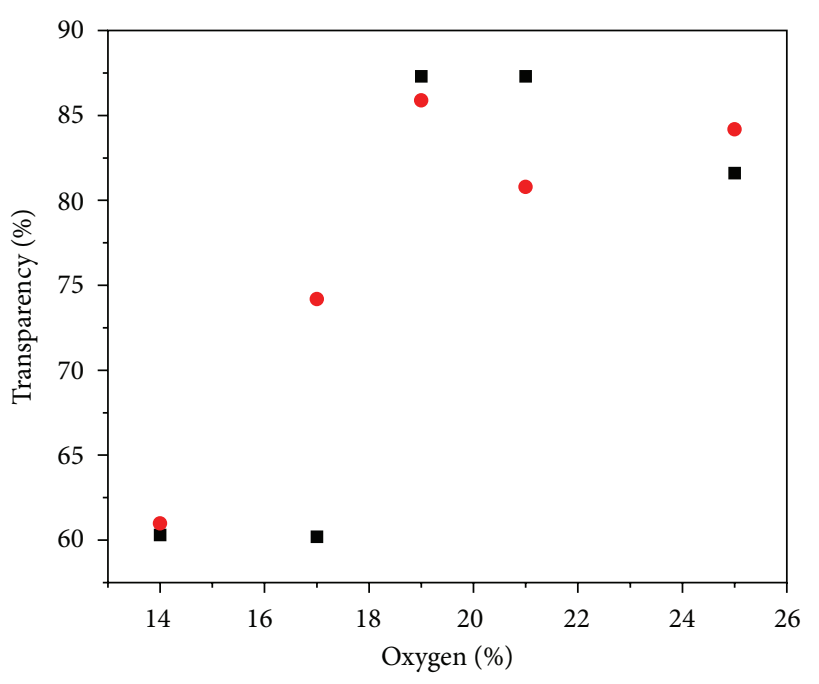

- As deposited

- Annealed

FIGURE 5: Transparency: comparison between as-deposited (before annealing) and annealed samples.

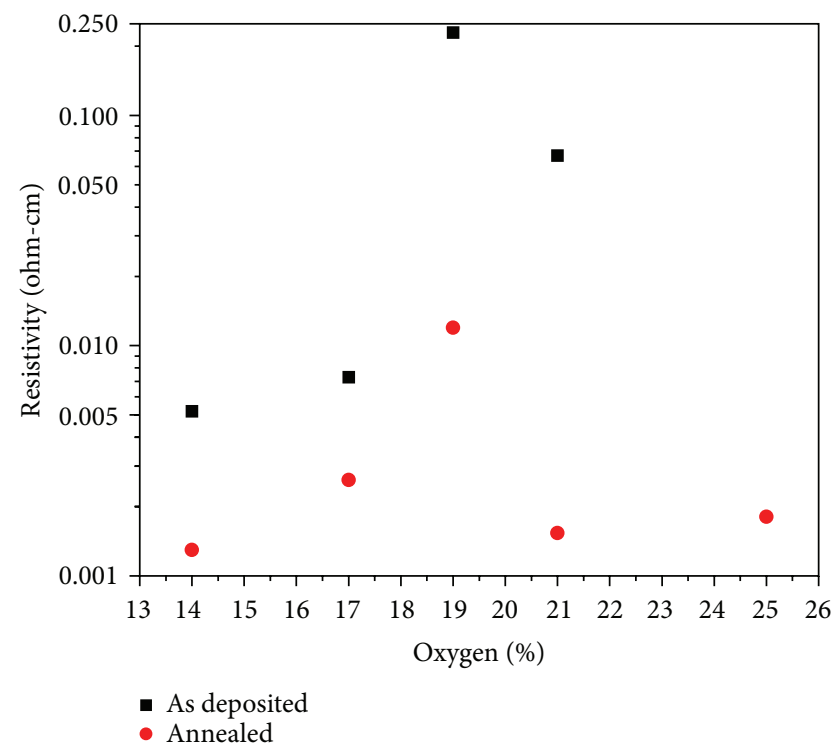

FIGURE 6: Resistivity: comparison between-as deposited (before annealing) and annealed samples.

Figure 8 shows the XRD results after annealing. It shows the single phase (hexagonal) formation of $\mathrm{ZnO}$ in the film, while film deposited at $14 \%$ oxygen environment still shows the $\mathrm{Zn}$ in the film. Presences of $\mathrm{Zn}$ in this sample also clarify the reason of low resistivity and low transparency in this particular sample.

3.4. SEM. Figure 9 shows the cross-section images of the films deposited in oxygen environment and annealed in reduced environment. It can be clearly seen from the images that, as oxygen percentage increases, columnar growth of the film increases while the film deposited at lower oxygen percentage (14\%) shows no columnar growth.

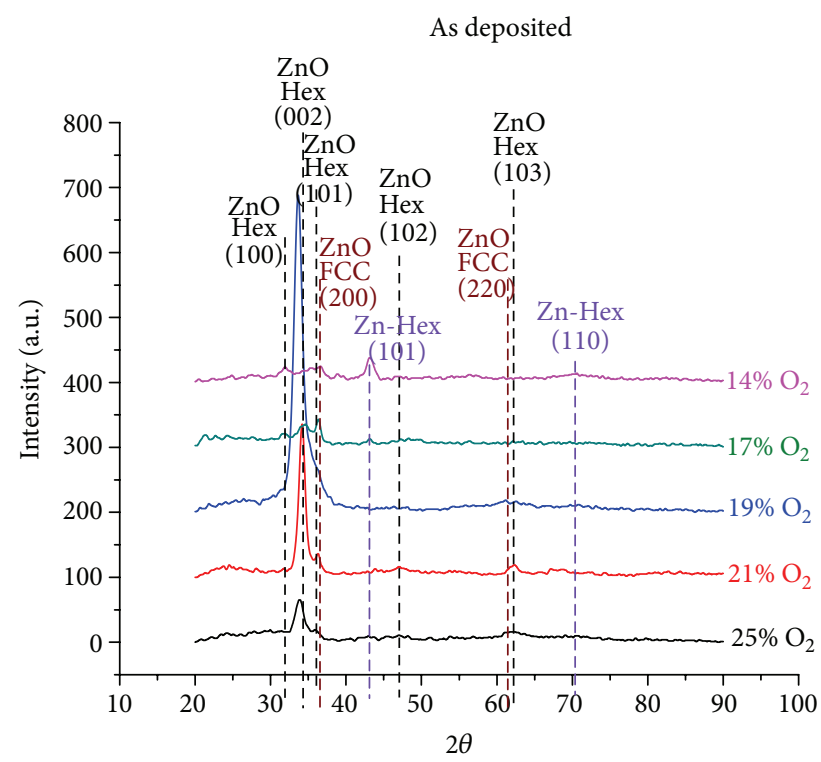

FIGURE 7: XRD results with oxygen variation before annealing (as deposited).

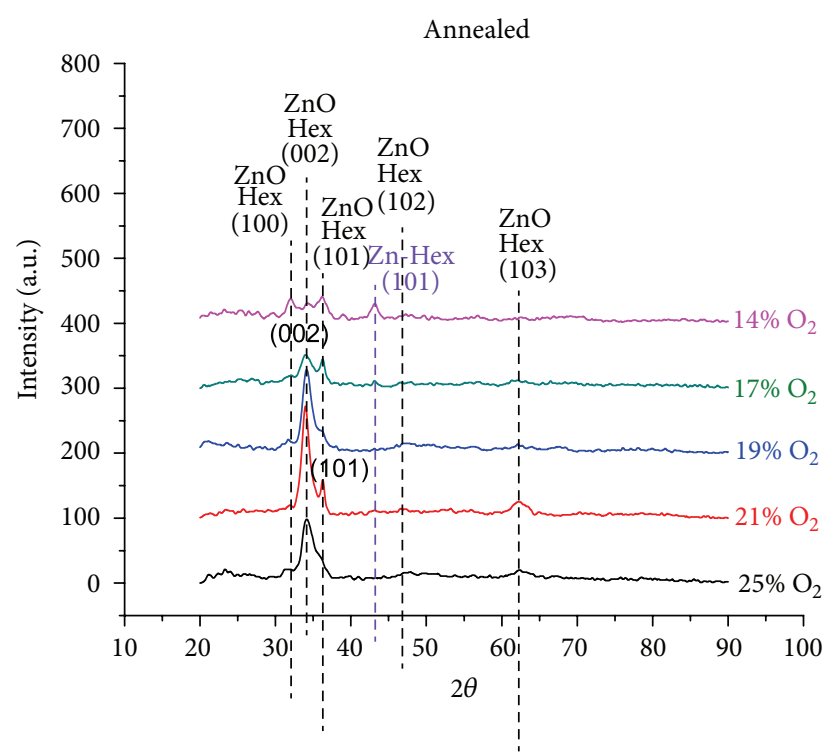

FIGURE 8: XRD results with oxygen variation before annealing (as deposited).

Figure 10 shows the surface images of films deposited in oxygen environment and annealed in reduced environment. Annealed film shows bigger grain size compare to the asdeposited films. Film deposited at 19\% oxygen shows the lowest grain size.

\section{Conclusion}

Approximate $600 \mathrm{~nm}$ thick film of $\mathrm{ZnO}$ deposited using DC magnetron sputtering on glass substrate. Deposited films achieve low resistivity after annealing in reduced environment due to desorption of oxygen from the film. Film deposited in $21 \%$ oxygen environment, shows $85 \%$ 
Sample ID

Cross section

$\left(\mathrm{O}_{2} \%\right)$

As deposited
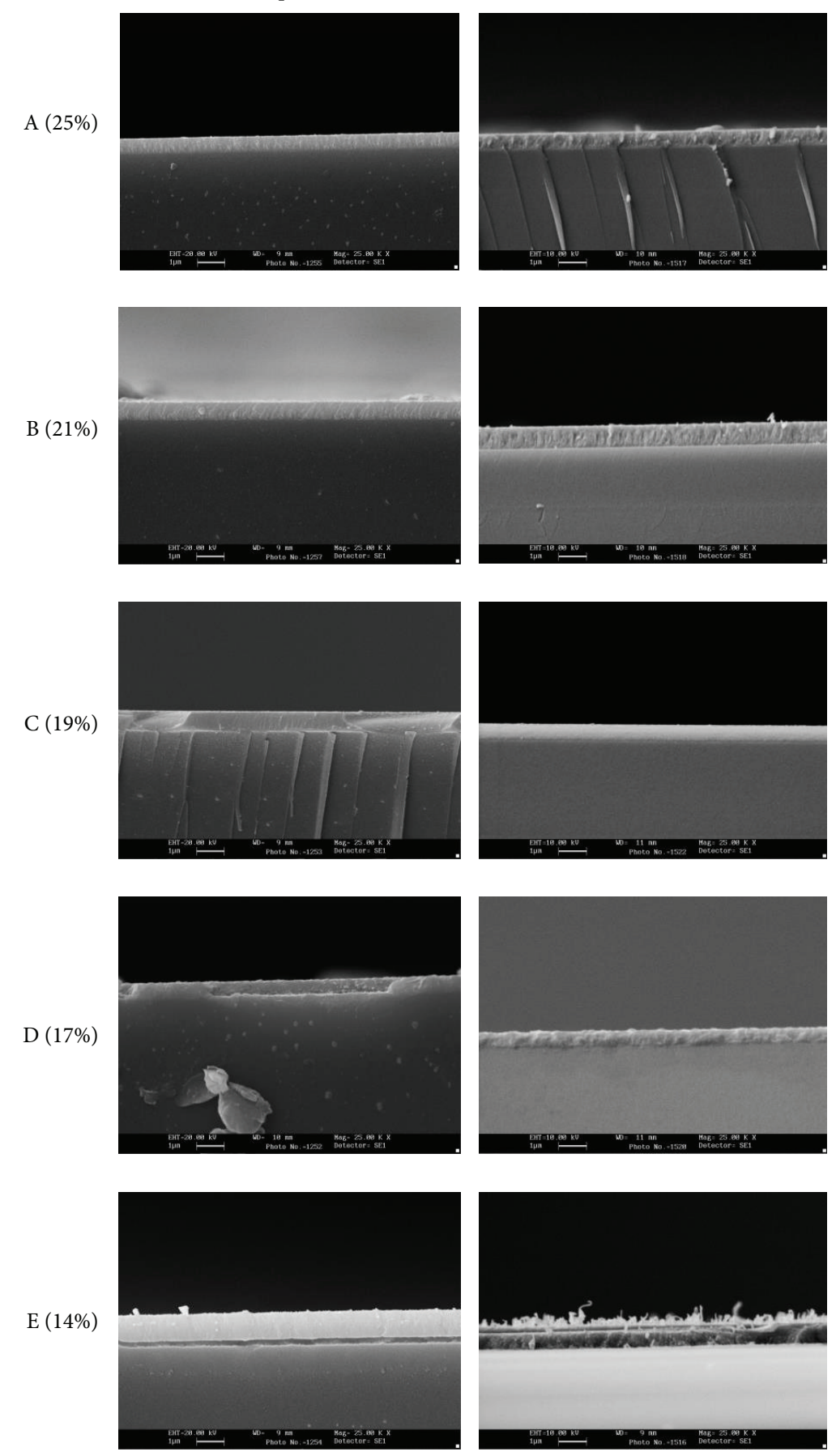

FIgURE 9: SEM images of the cross-section of the films (magnification $25 \mathrm{~K}$, scale $\sim 1 \mu \mathrm{m}$ ).

transparency, and after annealing at $300^{\circ} \mathrm{C}$ for two hours in reduced environment shows the $1.5 \times 10^{-3} \Omega \cdot \mathrm{cm}$ resistivity.

\section{Future Scope of Work}

Deposited $\mathrm{ZnO}$ film needs more improvement in terms of resistivity for TCO application of thin film solar cell. Doping of aluminum during deposition process is an option for decreasing the resistivity of the film. Doping should be less than $2 \%$ atomic weight to keep the transparency same [3].

\section{Acknowledgments}

The authors would like to acknowledge Dr. Balasubramanian, FCIPT, IPR, Gandhinagar, Gujarat, and Dr. Rajesh 


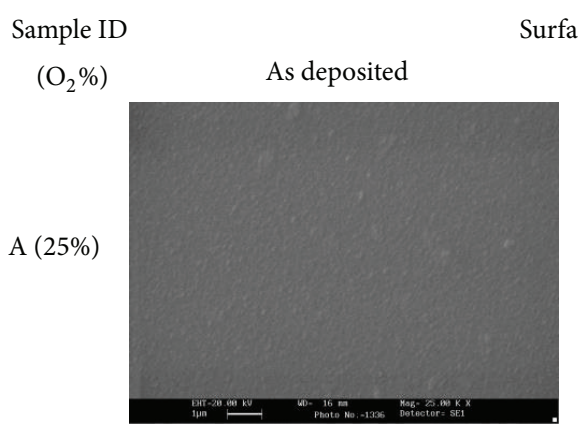

Surface
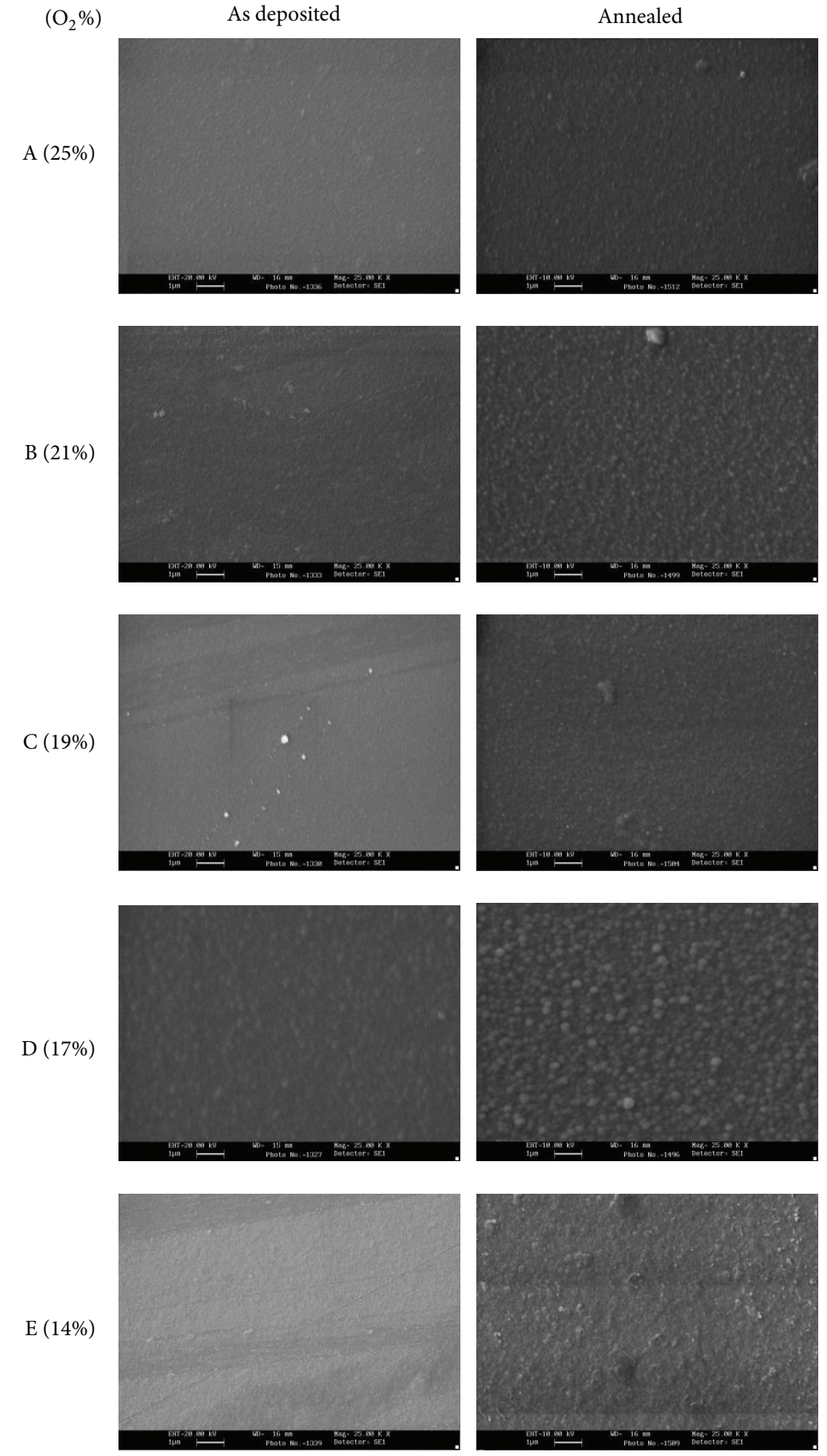

FIgURE 10: SEM images of the surface of the films (magnification $25 \mathrm{~K}$, scale $\sim 1 \mu \mathrm{m}$ ).

Babu, Forensic Science University, Gandhinagar, Gujarat, for arranging the spectrophotometer measurements, Mr. Narendra Chauhan, FCIPT, IPR, Gandhinagar, Gujarat, for performing SEM measurements, and Mr. Pratipal Rayjada, FCIPT, IPR, Gandhinagar, Gujarat, for performing XRD measurements. They would also like to acknowledge Department of Science and Technology, Government of India, for supporting this study under Grant DST/TM/SERI/2 K11/72.

\section{References}

[1] A. V. Singh, M. Kumar, R. M. Mehra, A. Wakahara, and A. Yoshida, "Al-doped zinc oxide ( $\mathrm{ZnO}: \mathrm{Al})$ thin films by pulsed laser ablation," Journal of the Indian Institute of Science, vol. 81, no. 5, pp. 527-533, 2001.

[2] K. Ellmer, F. Kudella, R. Mientus, R. Schieck, and S. Fiechter, "Influence of discharge parameters on the layer properties of 
reactive magnetron sputtered ZnO:Al films," Thin Solid Films, vol. 247, no. 1, pp. 15-23, 1994.

[3] K. Ellmer and R. Wendt, "D.c. And r.f. (reactive) magnetron sputtering of $\mathrm{ZnO}: \mathrm{Al}$ films from metallic and ceramic targets: a comparative study," Surface and Coatings Technology, vol. 93, no. 1, pp. 21-26, 1997. 

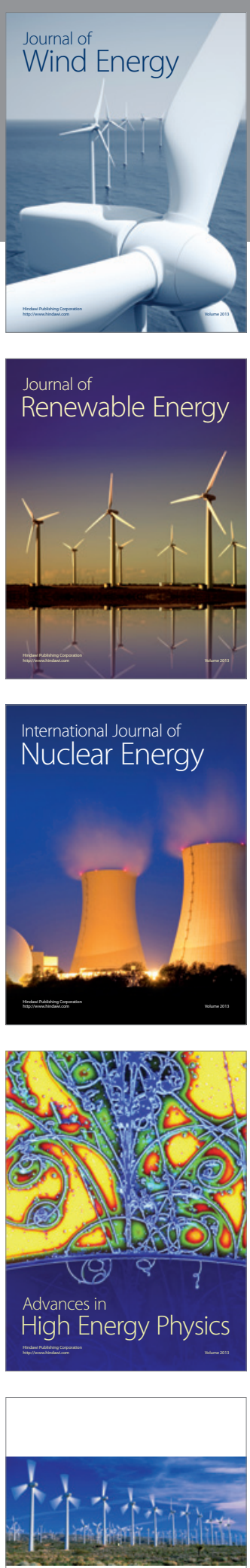

ISRN

Renewable Energy
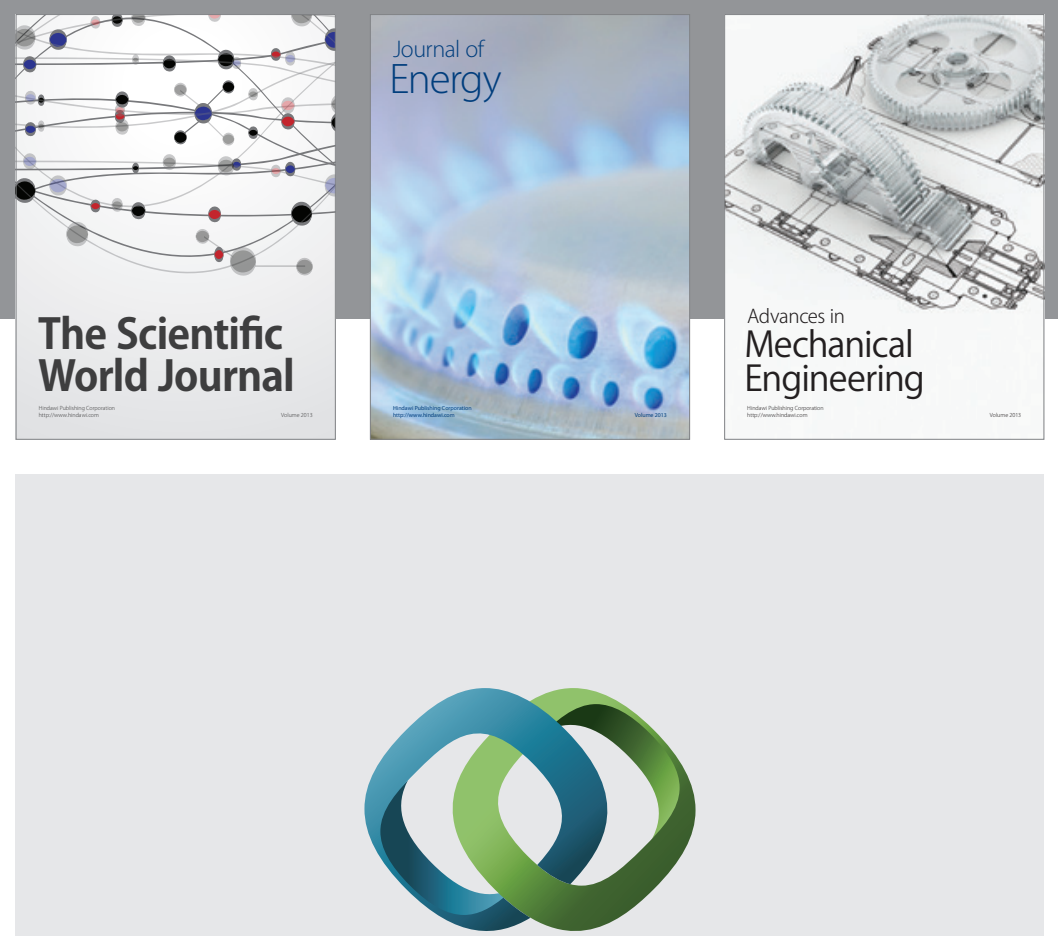

\section{Hindawi}

Submit your manuscripts at http://www.hindawi.com
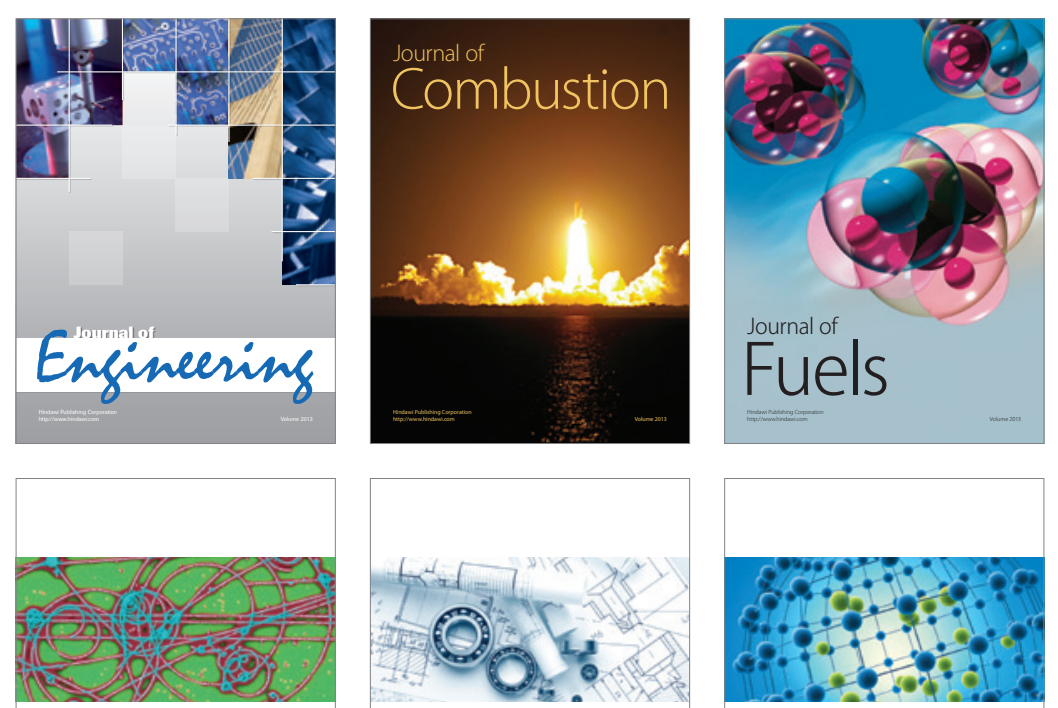

ISRN

High Energy Physics

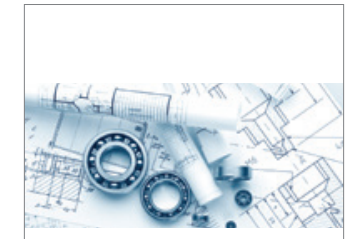

ISRN

Mechanical

Engineering

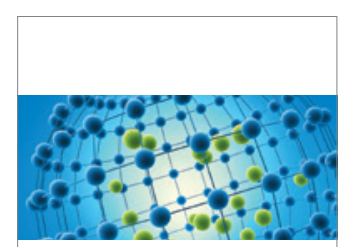

ISRN

Chemical

Engineering
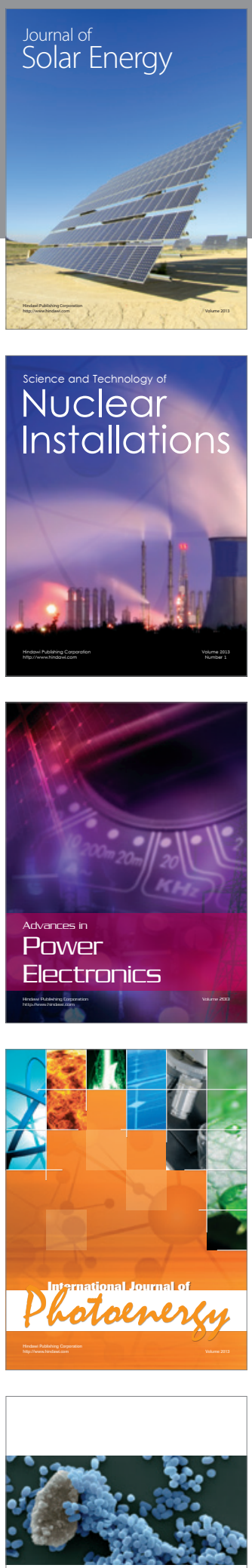

ISRN

Biotechnology 

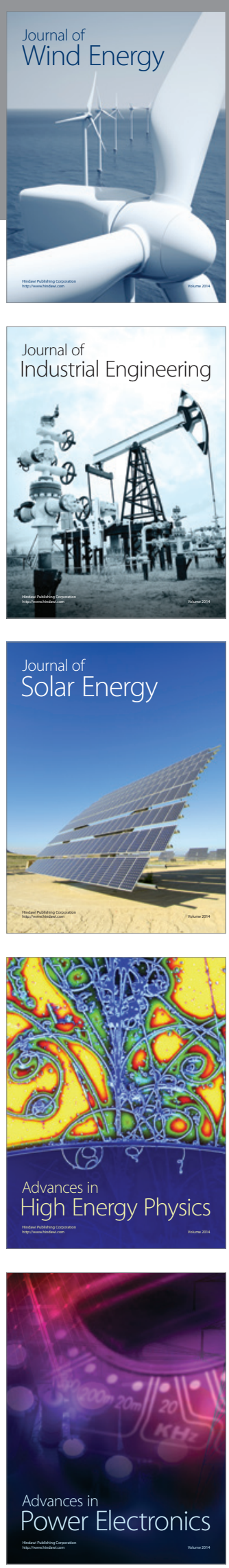
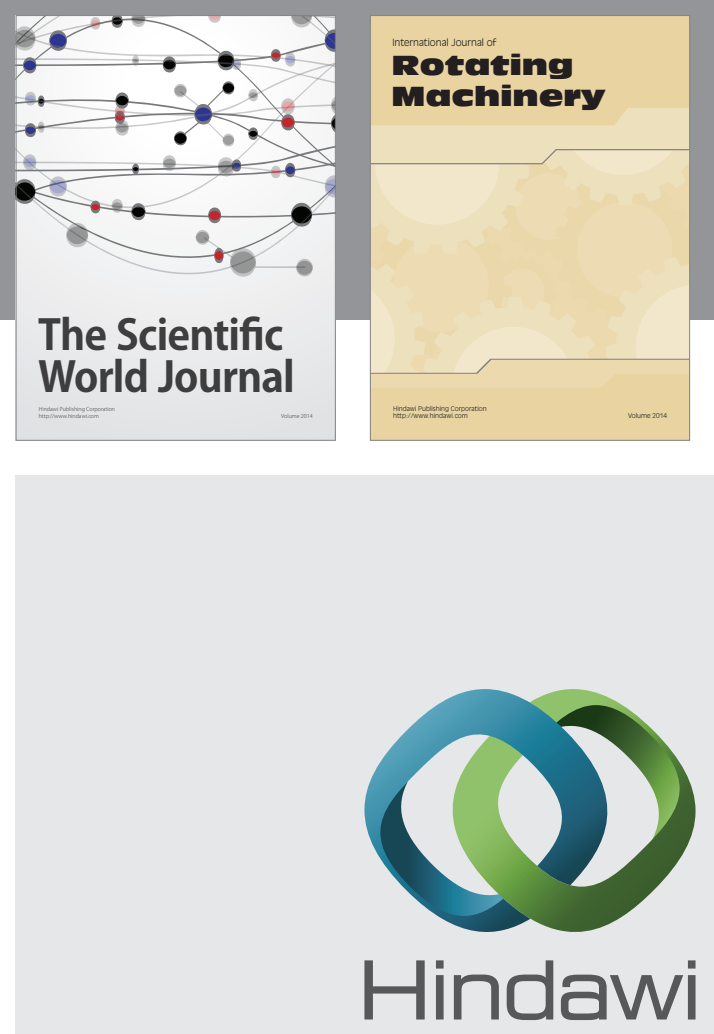

Submit your manuscripts at

http://www.hindawi.com
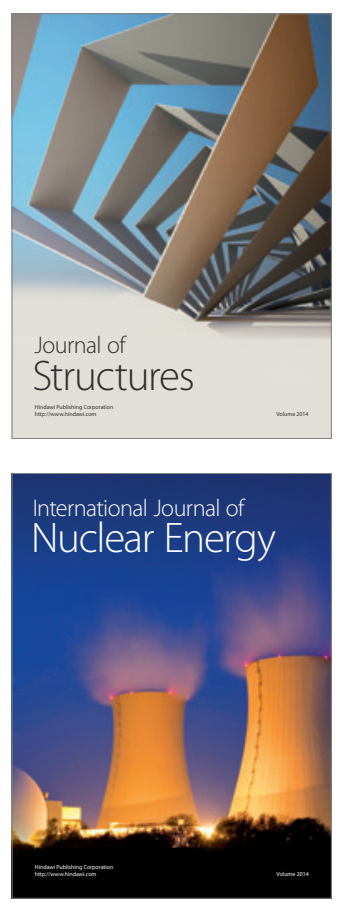
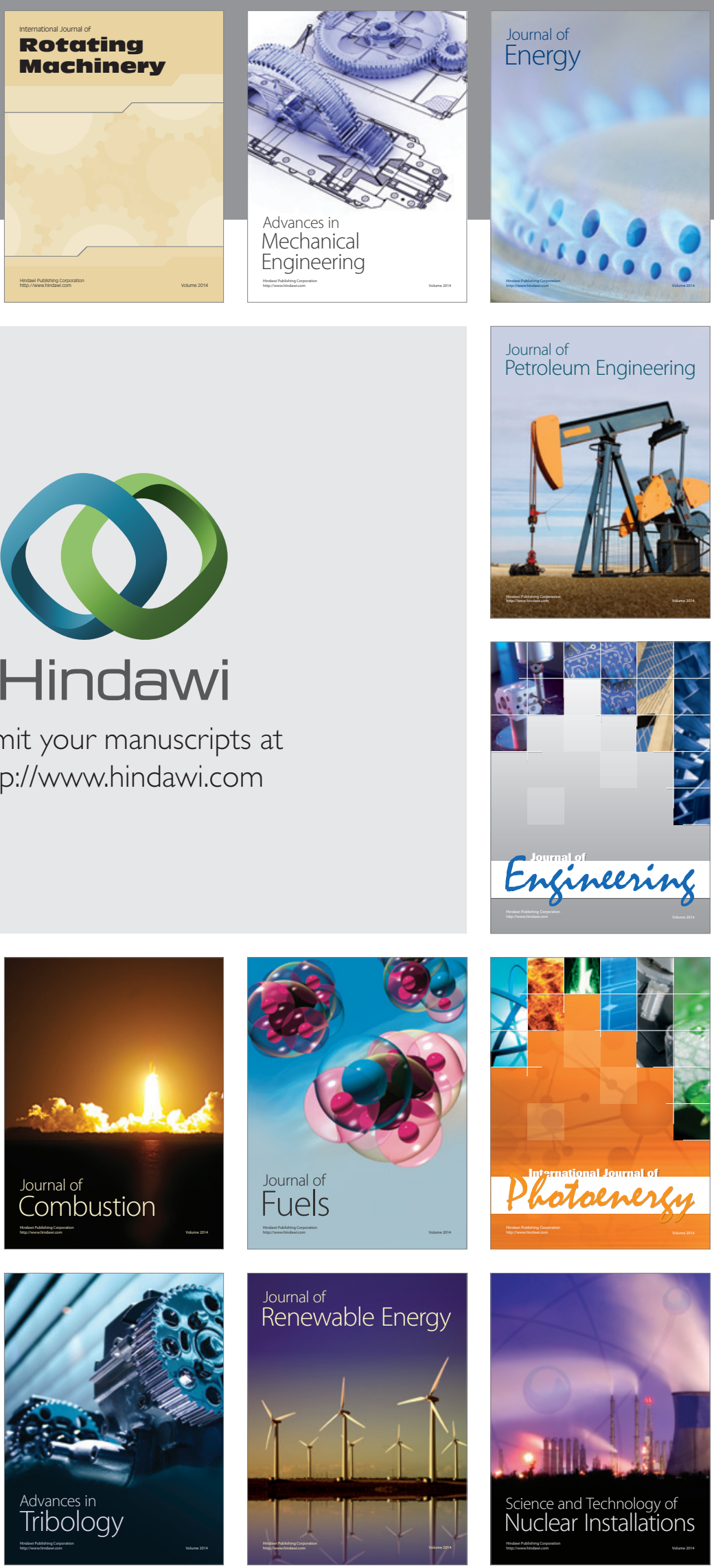